\title{
As renúncias tributárias das receitas previdenciárias no Brasil: uma expressão de captura do fundo público no período de 2013 a 2018
}

Tax waivers of social security revenues in Brazil: an expression of capture of the public fund in the period from 2013 to 2018

\author{
Fabrício Rodrigues da Silva* \\ Jordeana Davi**
}

\begin{abstract}
Resumo
No Brasil, o capital em crise tem sido socorrido pelo Estado através de um conjunto de medidas de ajuste fiscal, dentre elas, as renúncias tributárias. O objetivo deste artigo é apresentar e analisar as renúncias tributárias no orçamento das contribuições sociais das receitas previdenciárias no período de 2013 a 2018 e nas demais contribuições sociais da Seguridade Social. É necessário conhecer e analisar as renúncias e confrontá-las com os argumentos do déficit previdenciário, utilizados pelos governos brasileiros durante os últimos trinta anos para aprovar a contrarreforma da Previdência Social, que atualmente se expressa na Emenda Constitucional n. 103/19. Procedemos a uma revisão bibliográfica, bem como a uma pesquisa documental em relatórios financeiros. Os dados revelam, a partir dos valores renunciados no orçamento das contribuições sociais sobre a folha de salário das receitas previdenciárias e nas demais contribuições sociais da Seguridade Social no período descrito, uma apropriação do fundo público por tal mecanismo, comprometendo a garantia dos direitos previdenciários e beneficiando o capital financeiro.
\end{abstract}

Palavras-chave: Fundo público. Renúncias tributárias. Seguridade social. Previdência social. Brasil.

\begin{abstract}
In Brazil, the capital in crisis has been bailed out by the state through a set of fiscal adjustment measures, including tax waivers. The purpose of this article is to present and analyze the tax waivers in the budget of social contributions of welfare revenues in the period 2013 to 2018 and the other social contributions of Social security. It is necessary to know and analyze the resignations and confront them with the arguments of the welfare deficit, used by the Brazilian governments during the last thirty years, to approve the Counter-reformation of Social Welfare, which is currently expressed In Constitutional Amendment n.o 103/2019. We proceeded to a bibliographic review, as well as a documentary research in financial reports. The data reveal, based on the values of the renown in the budget of social contributions on the salary sheet of social Security income and other social contributions in the period described, an appropriation of the public Fund by This mechanism, compromising the guarantee of social security rights and benefiting financial capital.
\end{abstract}

Keywords: Public fund. Tax waivers. Social security. Social welfare. Brazil

\footnotetext{
* Mestre pelo Programa de Pós-Graduação em Serviço Social da Universidade Estadual da Paraíba (UEPB). Especialista em Ciências da Educação e Docência do Ensino Superior pelo Centro Universitário Vale do Salgado (UNIVS). Docente da graduação em Serviço Social do Instituto Federal de Educação, Ciência e Tecnologia do Ceará (IFCE). E-mail: fabricio.rodrigues@ifce.edu.br

** Doutora pelo Programa de Pós-Graduação em Serviço Social da Universidade Federal de Pernambuco (UFPE). Docente da graduação e pós-graduação em Serviço Social da Universidade Estadual da Paraíba (UEPB). E-mail: jordeana.pb.010@uol.com.br.
} 


\section{Introdução}

Uma nova etapa da contrarreforma da Previdência Social foi aprovada, sob o Governo de Jair Bolsonaro ${ }^{1}$ (sem partido), materializada na Emenda Constitucional n.o 103/19. Como se não bastassem as contrarreformas já realizadas nos governos anteriores (BEHRING, 2008b), por meio das Emendas Constitucionais n.ำ 20/98, no governo de Fernando Henrique Cardoso (Partido da Social Democracia Brasileira), e n. 41/03, no governo de Luís Inácio Lula da Silva (Partido dos Trabalhadores), e da Lei n.o 12.618/12, que criou a previdência complementar para os servidores públicos federais. Há ainda de se mencionar as Medidas Provisórias n.ํs 664 e 665, transformadas, respectivamente, nas leis n. $13.135 / 15$ e n.o 13.134/15, no Governo Dilma Rousseff (Partido dos Trabalhadores), que alteraram e restringiram direitos previdenciários e trabalhistas, e a tentativa do Governo Michel Temer (Movimento Democrático Brasileiro) de aprovar a Proposta de Emenda à Constituição n.o 287/2016. A nova contrarreforma, diferentemente de todas as outras, apresenta uma natureza mais perversa, tendo em vista o aprofundamento das alterações restritivas que dificultam o acesso da classe trabalhadora a previdência social.

A "nova previdência" desmonta a previdência pública construída pelos trabalhadores e inscrita na seguridade social brasileira como expressão de conquista e de proteção social, apesar dos avanços limitados, tendo em vista as particularidades de um país de capitalismo dependente e subordinado. Essa nova ofensiva se configura como mais uma tentativa de socorro ao capital, em crise desde os anos 1970 (MANDEL, 1990), sobretudo, para alimentar o principal desdobramento advindo de tal adversidade: a financeirização do capital (CHESNAIS, 2005).

Conforme afirmam os pesquisadores orgânicos da classe trabalhadora, o capital financeiro, a partir do processo de mundialização do capital, tem promovido a captura do fundo público brasileiro através de vários mecanismos, sendo o principal o sistema da dívida pública, transferindo parcelas significativas do fundo público para alimentar os rentistas (SALVADOR, 2010). Assim, em se tratando do Orçamento da Seguridade Social (OSS), a contrarreforma da Previdência Social significa liberar recursos que deveriam custear os benefícios previdenciários, tendo em vista que todas as alterações privam e impedem os trabalhadores do acesso, possibilitando que esses recursos economizados, atualmente

\footnotetext{
${ }^{1} \mathrm{O}$ resultado das eleições de 2018 é consequência da reação conservadora e mais uma etapa da ofensiva ultraliberal contra a classe trabalhadora.
} 
avaliados em mais de $\mathrm{R} \$ 1$ trilhão pelo Ministério da Economia, sejam liberados e o Brasil possa crescer e se desenvolver. Mas a realidade tem mostrado o contrário, fazendo-se necessário defender uma posição de questionamento a essas medidas e revelar a sua essência.

Para isso, destacamos que, por trás desses argumentos falaciosos e pouco convincentes do governo, está em atuação um conjunto de medidas de ajuste fiscal adotado pelo Estado e que evidencia o destino dos recursos do Orçamento Fiscal (OF) e do OSS, dentre elas: a Desvinculação de Receitas da União $(D R U)^{2}$ e as Renúncias Tributárias; a Lei de Responsabilidade Fiscal - Lei n. 101/2000³; o Superávit Primário4; a Emenda Constitucional n. 9 95/2016, que congela os gastos primários por 20 anos, o Programa de Refinanciamento $\left(\right.$ REFIS) ${ }^{5}$ da dívida e a não cobrança da dívida ativa dos devedores do Instituto Nacional do Seguro Nacional (INSS); e a prática dos juros altos.

Este artigo tem como objetivo apresentar e analisar as renúncias tributárias no orçamento das contribuições sociais das receitas previdenciárias no período de 2013 a 2018 e nas demais contribuições sociais da Seguridade Social, tendo em vista que as renúncias tributárias se constituem como uma das medidas de ajuste fiscal que socorrem o capital em tempos de crise.

Este artigo expõe os valores apropriados pelas renúncias tributárias no período destacado contrapondo com os argumentos de déficit previdenciário apontado pelo atual governo ${ }^{6}$ e pelos demais governos nos últimos trintas anos, já que o suposto déficit se configura como principal argumento dos ataques aos direitos previdenciários. Apresentamos, ainda, para enriquecer esta análise, os valores renunciados nas demais contribuições sociais

\footnotetext{
${ }^{2}$ Criada em 1995 no governo de Fernando Henrique Cardoso, no bojo da estabilização econômica e do Plano Real, sob a nomenclatura de Fundo Social de Emergência, transformando-se em 1997 em Fundo de Estabilização Fiscal, assumindo a nomenclatura de DRU a partir do ano de 2000. A DRU desvincula recursos do OSS e do OF para garantir as metas do superávit primário (FILGUEIRAS, 2000).

${ }^{3}$ Criada em 2000, com o objetivo de limitar as despesas em todas as esferas do poder executivo, voltadas especialmente, para aqueles gastos relacionados com pessoal, além de limitar o endividamento público, definir metas fiscais, criar um mecanismo de compensação para despesas permanentes e controlar as finanças públicas em anos de eleição. É usada como escudo pelos gestores, frente as demandas sociais por aumento nos gastos, sob o argumento do risco de estarem sujeitos a processos administrativos por improbidade, contudo, ela não tem limitado na prática os gastos financeiros, que são destinados ao pagamento do serviço da dívida pública.

${ }^{4}$ É o montante de recursos economizados pelo governo, cujo objetivo é o pagamento dos juros da dívida púbica.

${ }^{5}$ Criado pela Lei n. $13.485 / 2017$, autoriza o parcelamento das dívidas de devedores junto ao INSS, concedendo, ainda, descontos de $25 \%$ em multas e encargos e de $80 \%$ nos juros.

${ }^{6}$ Segundo a equipe econômica do governo Bolsonaro, em 2018, o déficit era de R\$ 195,2 bilhões (BRASIL, 2019c). Essa metodologia de cálculo considera apenas o saldo previdenciário, ou seja, a folha de salário, desconsiderando as demais contribuições sociais que compõem o OSS.
} 
da seguridade social, tendo em vista a importância de não se discutir o orçamento das contribuições sociais de forma fragmentada, pois todas elas constituem a totalidade do fundo público da seguridade social para custear as políticas de saúde, previdência e assistência social.

A partir da reflexão da realidade, somamos forças às frentes de luta da classe trabalhadora em defesa da Previdência Social. Para a leitura dessa realidade, recorremos à interpretação crítico-dialética, na perspectiva da totalidade e contradição. A discussão foi realizada com o auxílio de uma revisão de literatura e ainda de uma pesquisa documental em relatórios financeiros sobre o OSS no período de 2013 a 2018, tendo em vista o aprofundamento das renúncias tributárias nesse período, frente à crise do capital e às suas crescentes necessidades de acumulação.

O artigo está organizado em três eixos de análise: no primeiro abordamos algumas notas acerca da crise contemporânea do capital; no segundo discutimos o fundo público no contexto de crise do capital; e no terceiro e último eixo expomos, analisamos e problematizamos a apropriação do fundo público, por meio dos dados relacionados às renúncias tributárias no orçamento da Previdência Social, bem como das demais contribuições sociais do OSS no Brasil. Por fim, tecemos algumas considerações finais.

\section{Notas Acerca da Crise Contemporânea do Capital}

Nesta quadra histórica contemporânea, o sistema capitalista tem apresentando consequências significativas para a humanidade, refletindo o esgotamento das poucas possibilidades civilizatórias que a ordem tem a oferecer em todo o mundo, de forma mais intensiva nos países de capitalismo dependente, como no Brasil. Agudizam-se as expressões da questão social decorrentes desse sistema, em especial, no que se refere à desigualdade social ${ }^{7}$. São alarmantes os números do desemprego massivo em todo o globo ${ }^{8}$ que assola a

\footnotetext{
7 “Em 2016, 1\% da população mundial teve em suas mãos a metade da riqueza disponível no planeta” (TEIXEIRA, 2017, p. 100). Dados do Relatório da Fundação Getúlio Vargas de 2019 revelam que, diante da intensificação do programa de ajuste fiscal no Brasil, a desigualdade de renda aumentou no segundo semestre de 2019. De 2014 a 2019, a renda da metade mais pobre da população caiu $17,1 \%$, enquanto a renda dos $10 \%$ mais ricos teve aumento de $2,55 \%$ e o $1 \%$ mais rico teve ganhos de $10,11 \%$. A pesquisa ainda revela que a desigualdade atinge jovens com idades de 20 a 24 anos (NERI, 2019b).

${ }^{8}$ Segundo Teixeira (2017), fundamentada nos dados da Organização Internacional do Trabalho (2016) atualizados sobre o desemprego, a estimativa era de que, ao encerrar o ano de 2016, 199,4 milhões de pessoas estariam desempregadas no mundo. Em 2015, o contingente de desempregados alcançou a faixa de 197,1 milhões, sendo 27 milhões a mais em relação a meados de 2007. No Brasil, em 2016, a taxa de desocupação alcançou a marca de $11,2 \%$ da população economicamente ativa, correspondendo a 11,4 milhões de pessoas, saltando
} 
classe trabalhadora, refletindo-se em pobreza e extrema miséria ${ }^{9}$ ampliadas nos países, sobretudo, nos considerados de terceiro mundo. É também visível o acirramento da luta de classes - indiscutivelmente, nesse contexto, a classe trabalhadora vem sofrendo grandes derrotas, graças a retrocessos em termos de liberdades democráticas e avanços progressistas conquistados (MANDEL, 1990), com ênfase na destruição dos direitos sociais e na captura do fundo público pelo capital.

Apesar das significativas derrotas sofridas pelos trabalhadores, esta classe tem resistido, mesmo que na defensiva, construindo lutas, ainda que às vezes fragmentadas, contra as ofensivas do capital, seja nas ruas, nas brechas que a democracia liberal possibilita e, especialmente, no campo das ideias críticas, através da produção de conhecimento da realidade, revelando o caráter perverso desse sistema, que vem aprofundando a barbárie. $\mathrm{Na}$ defensiva, os trabalhadores têm construído uma agenda de lutas contra os ataques à previdência social, à educação e à legislação trabalhista, promovendo diversas paralisações e greves pelo Brasil $^{10}$, encabeçadas principalmente pelos docentes, discentes e técnicos das universidades públicas, somados às demais categorias de trabalhadores. São manifestações que tornam visível para a população a defesa dos direitos previdenciários e da educação pública e denunciam as estratégias do governo. É um começo.

Esse contexto de barbárie é decorrente das determinações advindas da crise do capitalismo contemporâneo, já que neste marco histórico da mundialização do capital predominam a financeirização (CHESNAIS, 2005), a refuncionalização do Estado (HARVEY, 2014), o assalto ao fundo público (SALVADOR, 2010) e outras consequências societárias.

Para compreender a crise atual, faz-se necessário uma visão histórica da acumulação do capital. O período que antecedeu a crise dos anos 1970 foi marcado pela combinação de

para $13,7 \%$ de desempregados no primeiro trimestre de 2017, o que corresponde a 14,2 milhões de desempregados, conforme dados da Pesquisa Nacional de Amostra por Domicílio/IBGE (SOUZA; SOARES, 2019). Em 2019, no primeiro trimestre registrou-se uma pequena queda no desemprego, alcançando a marca de 13 milhões de desempregados (IBGE, 2019).

${ }^{9}$ No Brasil, os números são alarmantes. Souza e Soares (2019) apresentaram dados atualizados da Síntese dos Indicadores Sociais do IBGE (2017). No ano de 2016, 25,4\% da população encontrava-se em situação de pobreza, vivendo com uma renda domiciliar per capita de aproximadamente $\mathrm{R} \$ 387,00$ ao mês, sendo que esses dados são elevados quando observados o Nordeste e o Norte, atingindo cerca de $43 \%$ da população dessas regiões. Ainda, as autoras apresentam os dados referentes à pobreza extrema, sendo que cerca de $4,2 \%$ da população nacional encontrava-se vivendo em 2016 com R\$ 85,00 per capita. 0 índice também aumenta quando observada a região Nordeste, onde $7,9 \%$ do total da população encontra-se em tal situação. Além de evidenciarem um drástico aumento, é perceptível também a intensificação dos números em regiões que são historicamente negligenciadas pelo Estado.

${ }^{10}$ Dentre as já realizadas, destacamos as greves gerais de 30 de maio de 2019 e 14 de junho de 2019. 
elementos a partir da necessidade de medidas contra as crises do capital, considerados como medidas anticíclicas. Os pilares que sustentaram os anos gloriosos do capitalismo se expressaram em duas estratégias: a primeira, advinda do pensamento econômico de Keynes - intervenção econômica do Estado - e, a segunda, do pensamento de Ford - produção e consumo em massa.

Estas estratégias formaram a combinação ideal para que o capitalismo pudesse registrar anos de expansão e se consolidar mundialmente (HARVEY, 1992). Esse modelo de regime de produção e regulação social foi significativo, não só para o capital, mas também para a classe trabalhadora, tendo em vista que, naquele momento histórico, instituiu-se o welfare state, a partir da ampliação do padrão de financiamento público na econômica capitalista pós-guerra (OLIVEIRA, 1998), contribuindo para a melhoria das condições de vida social dos trabalhadores. Entretanto, essa medida anticíclica se tornou obsoleta, já que “[...] o período de 1965 a 1973 tornou cada vez mais evidente a incapacidade do fordismo e do keynesianismo de conter as contradições inerentes ao capitalismo" (HARVEY, 1992, p. 135).

É importante destacar a natureza das crises do capital para compreendermos a problemática que assola essa quadra histórica. Mandel (1990), ao determinar a natureza da crise capitalista, destaca que não consiste na ausência de produção, como acontecia nas crises que antecederam o sistema capitalista, tendo em vista o não desenvolvimento das forças produtivas. Ressalta que o problema central reside na impossibilidade de venda de mercadorias com preços que garantam, no mínimo, o lucro médio do capital, portanto, configura-se como uma crise de superprodução de valores de troca, reforçando a ideia central de que a produção não é regida pelas necessidades humanas, mas, sim, pela necessidade de lucro, já que o modo de produção capitalista é de produção mercantil generalizada e necessita realizar na circulação o que investiu na produção. Mandel (1990) destaca que, para analisar as crises do capital, é importante considerar a imbricação orgânica entre superprodução de bens de consumo e a superacumulação, portanto, o ponto de partida é a relação "[...] nesse desdobramento entre mercadoria e o dinheiro, que deve realizar o seu valor de troca - e na contradição entre o valor de uso e o de troca dessa mesma mercadoria, que é estreitamente ligada a esse desdobramento [...]." (MANDEL, 1990, p. 210).

A crise contemporânea do capital pode ser compreendida a partir da primeira recessão generalizada nos anos de 1974 e 1975 como reação imediata ao fim dos anos gloriosos do capitalismo, já que não se conseguiu manter elevadas as taxas médias de lucro 
do capital (MANDEL, 1990). Após esse período de expansão do capitalismo do Pós-Segunda Guerra Mundial, as grandes potências econômicas imperialistas passaram a experimentar os temores de um esgotamento das taxas de lucro, fato que se arrasta até os dias atuais tanto nos países centrais quanto nos periféricos, onde se observa uma maior intensidade dos prejuízos dessa crise.

A partir desse contexto de crise, o capitalismo, nos países centrais, rompeu com todas as formas de regulação social e política, regimes de produção e intervenção do Estado estabelecidos no período anterior. Esse rompimento tem consequências significativas para o trabalho, já que a partir dele a classe trabalhadora passou a sofrer uma verdadeira ofensiva contra o contrato social acordado anteriormente. A predominância da combinação entre fordismo e keynesianismo foi sendo substituída no processo de transformação políticoeconômica do capitalismo no final do século XX, dando lugar a nova combinação do regime de acumulação flexível e modo de regulação social e política neoliberal (HARVEY, 1992).

As transformações societárias advindas da crise contemporânea do capital envolvem a totalidade social. Incidem diretamente no mundo do trabalho, flexibilizando as relações trabalhistas - menos trabalho protegido formal e mais contratos via subcontratação por tempo parcial e, sobretudo, desemprego estrutural, enfraquecimento do poder sindical dos trabalhadores, que se configurou como uma das peças centrais no período do fordismo nos processos produtivos -, provocando mudanças rápidas nos padrões do desenvolvimento desigual, quebrando a rigidez do fordismo e explorando novas atividades em novos espaços geográficos, a exemplo do setor de serviços e do interesse do capital por países subdesenvolvidos, entre outras consequências (HARVEY, 1992).

A crise do capital tem provocado consequências devastadoras para a humanidade. Em países de economia dependente, como o Brasil, esse quadro é intensificado, sobretudo em se tratando da socialização dos prejuízos. Assim, a agenda neoliberal tem executado suas medidas de flexibilização - das relações de trabalho -, de desregulamentação - das relações comerciais e financeiras - e da privatização - do patrimônio público, desde os anos 1990, a partir do início do amplo processo de contrarreforma do Estado (BEHRING, 2008b) e da intensa agenda de ajuste fiscal permanente construída em tempos de cultura da crise (MOTA, 2015).

Nesse contexto de ajuste fiscal permanente, todos os governos e executaram a agenda neoliberal, apesar das particularidades assumidas no interior de cada bandeira 
partidária, alguns de forma mais ortodoxa e outros de forma mais branda, mas, em se tratando do papel do Estado capitalista no processo de produção e reprodução social, todos, sem exceções, implementaram as recomendações e os ditames do capital em detrimento dos direitos dos trabalhadores, sobretudo, os que se referem à previdência social. Sobre o interesse inesgotável do capital sobre a previdência pública, Granemann (2012, p. 253) ressalta que "o fundo público de modo geral e o fundo público alocado na política social previdenciária, em particular, passou [sic] a funcionar como elemento basilar para as provisórias resoluções das crises". Vejamos, a seguir, como se dá esse processo a partir da análise do fundo público e do papel que ele assume neste estágio contemporâneo do capitalismo.

\section{Fundo Público no Contexto de Crise do Capital e Acumulação por Espoliação}

Para entender como ocorre o processo de disputa do fundo público e de sua captura pelo capital, através das renúncias tributárias, se faz necessário refletirmos sobre o fundo público na perspectiva histórica e de como ele se torna central na crise do capital, tendo em vista seu papel histórico tanto na acumulação do capital quanto na reprodução da força de trabalho.

O fundo público se torna central na dinâmica capitalista a partir da expansão do padrão de financiamento público, que ocorre nas economias centrais da sociedade capitalista no Pós-Segunda Guerra. Foi a partir da política keynesiana de intervenção econômica do Estado, usando o gasto público como medida anticíclica contra as crises do capital, que o fundo público se tornou o principal instrumento de financiamento público das economias capitalistas centrais. Assim, essas economias puderam construir o modelo de Estado de BemEstar Social como expressão do contrato social acordado entre trabalho e capital. À medida que o fundo público se faz presente na reprodução da força de trabalho através dos gastos sociais, garantindo a proteção social, também se faz presente no financiamento da acumulação de capital, assumindo uma função estrutural no capitalismo (OLIVEIRA, 1998).

O fundo público, segundo Behring (2008a), é composto de mais-valor, ou seja, de trabalho excedente, apropriado pelo Estado através da extração de recursos, seja em forma 
de impostos ou de contribuições sociais ${ }^{11}$, que são produzidos socialmente. "O fundo público associa-se direta e indiretamente aos processos de produção e reprodução ampliada do valor, embora ele não produza diretamente mais-valia" (TEIXEIRA, 2017, p. 101).

Salvador (2010) identifica quatro funções principais que o fundo público exerce nas economias capitalistas: financiamento do investimento capitalista, com concessões de desonerações tributárias, subsídios, incentivos fiscais, redução de tributos a empresas; transferência de recursos para a dívida pública e para os detentores do capital portador de juros, na forma de juros e amortização; fiança as condições favoráveis para o modo de produção capitalista, alocando recursos para meios de transporte e infraestrutura, investigação e pesquisa e renúncias fiscais para as empresas; asseguração das políticas sociais, proporcionando direitos e inserindo as pessoas nos mercados para consumo. É na peça mais visível do fundo público, os gastos orçamentários do Estado, que identificamos a alocação dos recursos, para onde eles vão e a quem estão beneficiando, a partir do interesse político de determinada classe.

Isso implica reconhecer a tensão entre capital e trabalho na captura do fundo público, configurando o debate não somente como uma peça técnica e econômica, mas, sobretudo, como um significado político e ideológico. Sua alocação representa a prevalência de interesse de uma das classes. Portanto, o fundo público alocado na política social, em especial na previdência social, representa uma conquista histórica da classe trabalhadora, todavia, essa alocação vem sendo questionada e atacada, tendo em vista que, na contemporaneidade, predomina uma nova natureza do capitalismo, que Harvey (2014) denomina de acumulação por espoliação ${ }^{12}$.

Nela, novos mecanismos de acumulação são criados, mas, também, os da acumulação primitiva estão mais consolidados e aprimorados, a exemplo do capital financeiro

\footnotetext{
${ }^{11}$ No Brasil, a composição do fundo público se dá através da extração de impostos, taxas e contribuições sociais, previstos constitucionalmente.

12 Harvey (2014) considera que o processo de acumulação do capital possui um caráter interminável, portanto, configura historicamente e geograficamente o capitalismo. Nesse sentindo, a acumulação por espoliação carrega consigo uma combinação contraditória da lógica econômica com os processos moleculares de acumulação, bem como as estratégias diplomáticas, políticas e militares. Dessa forma, a acumulação por espoliação pode ser entendida como uma acumulação via saque, tendo em vista que o Estado e os direitos sociais estão sendo fortemente saqueados, predominantemente, pelo capital financeiro. $\mathrm{O}$ autor destaca a importância do sistema da dívida pública e do orçamento público frente às necessidades de acumulação e que, a partir da disputa de classes, tem sido o orçamento público saqueado pelo capital. O bloqueio pela burguesia do acesso da classe trabalhadora às instituições democráticas, políticas e jurídicas tem possibilitado esse saque, que é de natureza global.
} 
e do sistema de crédito. Predominam, na cena contemporânea, as ações fraudulentas, o saque das nações através do sistema da dívida pública, ataques especulativos, a criação de novos direitos de propriedade, agora relacionados também à intelectualidade, a exemplo do patenteamento e licenciamento de material genético. Registra-se também o processo de transformação das formas culturais em mercadorias, da privatização de bens públicos incluindo as universidades públicas, a privatização de bens naturais, como energia e água, e uma nova etapa de expropriação de terras comunais e de destruição da natureza (HARVEY, 2014).

Dentre tais características, destacamos a intensificação da destruição dos estatutos que regulam a proteção dos direitos do trabalho, transferindo do público para o mercado, por exemplo, o direito a aposentadoria e demais direitos sociais (HARVEY, 2014). Portanto, uma das formas de acumulação por espoliação realizada pelo capitalismo contemporâneo se dá sobre as reservas constituídas pelo trabalhador e acumuladas no fundo público, sobretudo, da seguridade social brasileira, para o financiamento da proteção social, através das políticas de Saúde, Previdência Social e Assistência Social. Como já destacado, esses recursos são transferidos para a esfera financeira via sistema da dívida pública, e as políticas sociais são transformadas em nichos de investimentos privados na modalidade de mercantilização de serviços.

Essa orquestra é regida pelo capital, que tem hoje como carro-chefe o capital financeiro, uma grande força que se realiza a partir do roubo e da fraude, tendo em vista o seu estilo especulativo e predatório (HARVEY, 2014). O seu florescimento aconteceu a partir da crise contemporânea do capital nos anos 1970, mas a sua intensificação ocorre a partir do que Chesnais (2005) denomina de hipertrofia do capital financeiro no processo de mundialização do capital nos anos 1980. Entram em cena as instituições financeiras, os fundos de pensão, predominando os investimentos financeiros que logram lucros sem sair da esfera financeira, através de juros altos de empréstimos, dividendos e pagamentos advindos de títulos e posses de ações. Resta destacar que esses lucros se constituem do trabalho excedente, da mais-valia socialmente produzida pelo trabalho, que em tal contexto, é intensificada para manter o pagamento dos juros altos, desencadeando, de forma mais intensa, a alteração tanto na composição orgânica do capital, quanto na produção de maisvalia absoluta e mais-valia relativa (MARX, 2008). 
Nesse contexto, são criados os arranjos necessários capazes de capturar o fundo público, em especial do OSS. Trataremos, a seguir, de explicitar essa captura através de uma das medidas de ajuste fiscal que socorrem o capital na atualidade: as renúncias tributárias no âmbito do orçamento da Previdência Social e das demais contribuições sociais da seguridade social brasileira.

\section{Renúncias Tributárias e a Captura do Fundo Público}

As renúncias tributárias fazem parte de um conjunto de políticas de ajuste fiscal que vem sendo adotado pela política econômica no Brasil. No âmbito da Receita Federal brasileira, as renúncias tributárias são conceituadas como gastos tributários, concedidas através do sistema tributário, objetivando atender interesses econômicos e sociais. A partir da sua concessão, ocorre a redução da arrecadação potencial, possibilitando que os valores fiquem disponíveis para o contribuinte. É importante destacar que os gastos tributários se constituem como uma medida de exceção do sistema tributário brasileiro (BRASIL, 2019a), mas, pelo que analisaremos a seguir, tal exceção tem sido permanente e intensiva no âmbito das contribuições sociais.

A realidade tem mostrado que essas são medidas importantes de socorro ao capital, tendo em vista o processo de crise contemporânea. Assim elas fazem parte das "[...] principais medidas para a retomada das taxas de lucro do capital: o desmonte das políticas sociais; o avanço privado sobre os recursos do fundo público, em especial no que tange à dívida pública e às desonerações tributárias [...]" (SOUZA, SOARES, 2019, p. 11).

Vejamos, na Tabela 1, os dados das renúncias tributárias nas contribuições sociais da Previdência Social, observando a sua evolução no período estudado e quais setores elas beneficiam, bem como o comportamento do crescimento nos respectivos anos:

Tabela 1 - Renúncias Tributárias nas contribuições da Previdência Social (valores correntes em bilhões de reais)

\begin{tabular}{lcccccc}
\hline \multicolumn{7}{c}{ ESTIMATIVAS BASES EFETIVAS } \\
\hline & $\mathbf{2 0 1 3}$ & $\mathbf{2 0 1 4}$ & $\mathbf{2 0 1 5}$ & $\mathbf{2 0 1 6}$ & $\mathbf{2 0 1 7}$ & $\mathbf{2 0 1 8}$ \\
\hline Simples Nacional & 18.267 & 19.535 & 22.495 & 23.766 & 24.419 & 25.828 \\
$\begin{array}{l}\text { Desonerações da folha de } \\
\text { salários }\end{array}$ & 12.284 & 22.107 & 25.199 & 14.547 & 13.336 & 14.110 \\
$\begin{array}{l}\text { Entidades filantrópicas } \\
\text { Exportação da produção }\end{array}$ & 8.720 & 10.428 & 97.55 & 10.236 & 10.518 & 11.125 \\
rural & 4.484 & 4.638 & 5.941 & 6.040 & 6.558 & 6.920 \\
& & & & & &
\end{tabular}




\begin{tabular}{lcccccc}
\hline Funrural & 0 & 0 & 0 & 0 & 0 & 1.104 \\
$\begin{array}{l}\text { Microempreendedor } \\
\text { Individual - MEI }\end{array}$ & 786 & 991 & 1.404 & 1.676 & 2.061 & 2.180 \\
Outras & 227 & 256 & 274 & 286 & 226 & 235 \\
\hline Total & $\mathbf{4 4 . 7 6 8}$ & $\mathbf{5 7 . 9 5 5}$ & $\mathbf{6 5 . 0 6 8}$ & $\mathbf{5 6 . 5 5 1}$ & $\mathbf{5 7 . 1 1 8}$ & $\mathbf{6 1 . 5 0 2}$ \\
\hline
\end{tabular}

Fonte: Elaboração própria com base nos dados da Anfip (2018).

$\mathrm{Na}$ série histórica apresentada acima, podemos destacar alguns elementos relevantes para análise. As renúncias tributárias no âmbito das contribuições sociais previdenciárias estão em caráter contínuo e crescente, apesar de algumas variações, como nos casos dos anos de 2016 e 2017. Esse fato sustenta nossa análise de que todos os governos $^{13}$ citados executaram a agenda neoliberal, já que as renúncias tributárias se constituem como uma das medidas de ajuste fiscal de socorro ao capital em crise. A soma de valores subtraídos com as renúncias das contribuições previdenciárias no período corresponde ao total de $\mathrm{R} \$ 342,9$ bilhões. De tal modo, se há um déficit nas contas da previdência, ele poderia ser facilmente sanado, por exemplo, com a suspensão das renúncias tributárias. Portanto, quem tem causado o desequilíbrio no orçamento previdenciário não são os benefícios, mas as medidas fiscais e políticas que o próprio Estado brasileiro promove, como o desemprego, a informalidade do trabalho, as renúncias tributárias e a DRU, entre outras medidas.

Uma outra observação relevante é em relação ao comportamento das renúncias tributárias no ano de 2015, em comparação aos anos de 2013 e 2014. Apesar do aumento progressivo nos respectivos anos, 2015 se destaca pelo aprofundamento dessa medida, tendo em vista o expressivo aumento, ou seja, o fenômeno do boom das renúncias tributárias.

A intensificação do uso das renúncias tributárias em 2015 se constituiu como principal instrumento de sustentação do mandato de Dilma Rousseff, tendo em vista o acirramento da luta de classes, frente às exigências da classe dominante diante da necessidade de recomposição da taxa de lucros em face da crise do capital. A exemplo da tentativa de legitimação, foi nomeado para o Ministério da Fazenda, em 2015, o banqueiro Joaquim Levy, de perfil liberal ortodoxo, que executou as trágicas medidas já citadas em favor

\footnotetext{
${ }^{13}$ Apesar de começar em 2013, esta série histórica não exclui os governos anteriores. Entre os motivos, podemos destacar que a realidade concreta sempre mostrou a vertente de orientação do Governo Fernando Henrique Cardoso, que, inclusive, sacrificou a política social para concretizar o Plano Real. No caso do Governo Lula, além de também ter executado medidas de ajuste fiscal, inspirou a política econômica do Governo Dilma, que deu continuidade ao tripé: câmbio flutuante, metas da inflação e superávit primário.
} 
do equilíbrio fiscal e em detrimento dos direitos da classe trabalhadora. Mas as medidas adotadas foram insuficientes para sustentar o governo, fato que culminou no golpe jurídicoparlamentar expresso no impeachment da Presidenta Dilma Rousseff, eleita democraticamente.

Todavia, as consequências das medidas tomadas pelo Governo Dilma em nome do ajuste fiscal de 2015 no cenário de recessão econômica acabaram por provocar a desaceleração da economia, que desencadeou um amplo processo de desemprego, acarretando a redução das contribuições sociais da previdenciária social, tendo em vista a sua dependência do mercado de trabalho formal. O ajuste fiscal de 2015 instaurou um círculo vicioso composto pelo corte de gastos, queda de crescimento, queda na arrecadação e piora no resultado fiscal (GENTIL, 2016).

Essas renúncias tributárias ${ }^{14}$ são referentes apenas à contribuição social sobre a folha de salário, que é composta da contribuição dos empregadores, portanto, trabalho excedente e mais-valia que deveriam financiar a proteção social dos trabalhadores da previdência social. Como já observamos, com base em Salvador (2010), uma das funções do fundo público é a concessão de renúncias tributárias às empresas com recursos que compõem o OF, contudo, neste caso, os valores acima renunciados não pertencem a este, mas, sim, ao orçamento das contribuições sociais previdenciárias que compõem o OSS. O Estado tem socorrido o capital com recursos próprios das contribuições sociais para a Previdência Social, em particular, e das demais contribuições sociais da Seguridade Social. As Tabelas 2, 3 e 4, a seguir, mostram a incidência das renúncias tributárias nas demais contribuições sociais:

Tabela 2 - Renúncias Tributárias em Contribuição Social sobre o lucro líquido (valores correntes em bilhões de Reais) ${ }^{15}$.

\begin{tabular}{lcccccc}
\hline \multicolumn{7}{c}{ ESTIMATIVAS BASES EFETIVAS } \\
\hline Simples Nacional & $\mathbf{2 0 1 3}$ & $\mathbf{2 0 1 4}$ & $\mathbf{2 0 1 5}$ & $\mathbf{2 0 1 6}$ & $\mathbf{2 0 1 7}$ & $\mathbf{2 0 1 8}$ \\
\hline Entidades filantrópicas & 6.389 & 7.005 & 6.710 & 7.044 & 7.358 & 7.825 \\
Inovação tecnológica & 1.707 & 1.824 & 1.163 & 1.221 & 1.276 & 1.357 \\
& 433 & 463 & 487 & 511 & 534 & 568
\end{tabular}

\footnotetext{
${ }^{14}$ As respectivas bases legais que sustentam as renúncias tributárias sobre contribuições da Previdência Social identificadas no período aqui analisado são: Lei n.o 12.546/12, art. 7o a 11ㅇ; Lei n.o 12.715/12, art. 55 e 56 ; Lei n. 12.794/13, art. 1ㅇ e 2ㅇ; MP n.ㅇ 601/12; MP n.o 612/13, art. 25으 e 26ㅇ; Lei n.o 12.844/13; MP n.ㅇ 651/14, art. 41으, Lei $n$. ㅇ 13.043/14, art. 53으, Lei n. 13.161/15 e Lei $n .0$ 13.202/15, todas com tempo indeterminado de vigência (BRASIL, 2019a). Neste sentido, é preocupante o nível de representação dos interesses da classe trabalhadora no sistema democrático brasileiro, já que todas essas legislações foram apreciadas e votadas pelos parlamentares.

${ }^{15}$ A soma de valores renunciados no período corresponde ao total de $R \$ 57,9$ bilhões.
} 
As renúncias tributárias das receitas previdenciárias no Brasil: uma expressão de captura do fundo público...

\begin{tabular}{lcccccc}
\hline Previdência Privada fechada & 193 & 206 & 216 & 227 & 237 & 252 \\
Prouni & 174 & 186 & 346 & 363 & 379 & 403 \\
Outras & 151 & 174 & 147 & 127 & 132 & 141 \\
\hline Total & $\mathbf{9 . 0 4 7}$ & $\mathbf{9 . 8 5 8}$ & $\mathbf{9 . 0 6 9}$ & $\mathbf{9 . 4 9 3}$ & $\mathbf{9 . 9 1 6}$ & $\mathbf{1 0 . 5 4 6}$ \\
\hline
\end{tabular}

Fonte: Elaboração própria com base nos dados da Anfip (2018).

Tabela 3 - Renúncias Tributárias em Contribuição para o financiamento da Seguridade Social (valores correntes em bilhões de Reais) ${ }^{16}$.

\begin{tabular}{|c|c|c|c|c|c|c|}
\hline \multicolumn{7}{|c|}{ ESTIMATIVAS BASES EFETIVAS } \\
\hline & 2013 & 2014 & 2015 & 2016 & 2017 & 2018 \\
\hline Desonerações da Cesta Básica & 11.512 & 12.303 & 12.951 & 13.595 & 14.202 & 15.103 \\
\hline Entidades filantrópicas & 4.741 & 5.066 & 5.328 & 5.593 & 5.842 & 6.213 \\
\hline Medicamentos & 2.882 & 3.734 & 3.898 & 5.480 & 5.725 & 6.088 \\
\hline $\begin{array}{l}\text { Produtos químicos e } \\
\text { farmacêuticos }\end{array}$ & 712 & 429 & 1.565 & 2.033 & 1.941 & 2.064 \\
\hline Simples Nacional & 17.237 & 18.969 & 18.809 & 19.745 & 20.627 & 21.935 \\
\hline Transporte coletivo & 610 & 1.155 & 1.268 & 1.331 & 1.391 & 1.479 \\
\hline Zona Franca de Manaus & 5.546 & 5.044 & 5.625 & 5.297 & 5.955 & 6.332 \\
\hline Outras & 11.529 & 13.167 & 12.878 & 6.838 & 6157 & 6.154 \\
\hline Total & 54.769 & 59.867 & 62.322 & 59.912 & 61.840 & 65.368 \\
\hline
\end{tabular}

Fonte: Elaboração própria com base nos dados da Anfip (2018).

Tabela 4 - Renúncias Tributárias em Contribuição Social para o PIS-PASEP (valores correntes em bilhões de Reais) ${ }^{17}$.

\begin{tabular}{lcccccc}
\hline \multicolumn{7}{c}{ ESTIMATIVAS BASES EFETIVAS } \\
& $\mathbf{2 0 1 3}$ & $\mathbf{2 0 1 4}$ & $\mathbf{2 0 1 5}$ & $\mathbf{2 0 1 6}$ & $\mathbf{2 0 1 7}$ & $\mathbf{2 0 1 8}$ \\
\hline $\begin{array}{l}\text { Desonerações da Cesta } \\
\text { Básica }\end{array}$ & 2.497 & 2.669 & 2.809 & 2.949 & 3.081 & 3.276 \\
$\begin{array}{l}\text { Medicamentos } \\
\text { Produtos químicos e }\end{array}$ & 611 & 792 & 827 & 1.162 & 1.214 & 1.291 \\
farmacêuticos & 133 & 80 & 329 & 432 & 416 & 443 \\
Simples Nacional & 3.848 & 4.226 & 4.193 & 4.402 & 4.598 & 4.890 \\
Zona Franca de Manaus & 1.181 & 1.072 & 1.201 & 1.137 & 1.280 & 1.361 \\
Outras & 2.069 & 2.369 & 2.413 & 1.095 & 929 & 903 \\
\hline Total & $\mathbf{1 0 . 3 3 9}$ & $\mathbf{1 1 . 2 0 8}$ & $\mathbf{1 1 . 7 7 2}$ & $\mathbf{1 1 . 1 7 7}$ & $\mathbf{1 1 . 5 1 8}$ & $\mathbf{1 2 . 1 6 4}$
\end{tabular}

Fonte: Elaboração própria com base nos dados da Anfip (2018).

A análise das renúncias tributárias sobre as demais contribuições sociais do OSS indica que incidem de forma mais intensa na Contribuição para o Financiamento da Seguridade Social (COFINS) e na folha de salário. Sobre a COFINS, o socorro é direcionado ao

\footnotetext{
${ }^{16}$ A soma de valores renunciados no período corresponde ao total de $\mathrm{R} \$ 364$ bilhões.

${ }^{17}$ A soma de valores renunciados no período corresponde ao total de R\$ 68,1 bilhões.
} 
grande capital privado, já que essa contribuição é paga pelas grandes empresas. Além de não pagarem as devidas contribuições, ainda há - por exemplo - um outro agravante evolvendo algumas dessas empresas: a dívida ativa do Instituto Nacional do Seguro Social (INSS). A Associação Nacional dos Auditores Fiscais da Receita Federal do Brasil (ANFIP) ${ }^{18}$ destaca que, segundo a Procuradoria-Geral da Fazenda Nacional (PGFN), os valores devidos ao INSS são da ordem de R\$ 426 bilhões, em 2016. Entre os maiores devedores, estão os governos estaduais e municipais, empresas e fundações, mas também podemos destacar bancos como Bradesco e Caixa Econômica Federal e empresas como Vale, Marfrig Global Foods e JBS.

Outro destaque é que há maior incidência de renúncias no Simples Nacional. Este é aplicável às Microempresas e Empresas de Pequeno Porte, configurando-se como um regime tributário diferenciado, simplificado e favorecido, previsto na Lei Complementar $n . .9123$, de 14.12.2006 (BRASIL, [2019]). Assim, a tendência do empreendedorismo tem encontrado subsídios para sua sustentação através do Estado, já que o Simples facilita a gestão dos tributos, atraindo pessoas para abrirem empresas.

No mais, observamos alguns outros setores que são beneficiados, como, por exemplo, indústrias químicas, farmacêuticas e de medicamentos; indústrias inseridas na Zona Franca de Manaus; entidades filantrópicas - que neste cenário contemporâneo também voltam a ganhar espaço na proteção social, assumindo responsabilidades que são do Estado - e produtos exportados pelo agronegócio.

O Gráfico 1 sintetiza as renúncias tributárias totais no OSS, confirmando a captura desse orçamento.

Gráfico 1 - Evolução das Renúncias Tributárias nas Contribuições Sociais do Orçamento da Seguridade Social (valores correntes em bilhões de Reais)

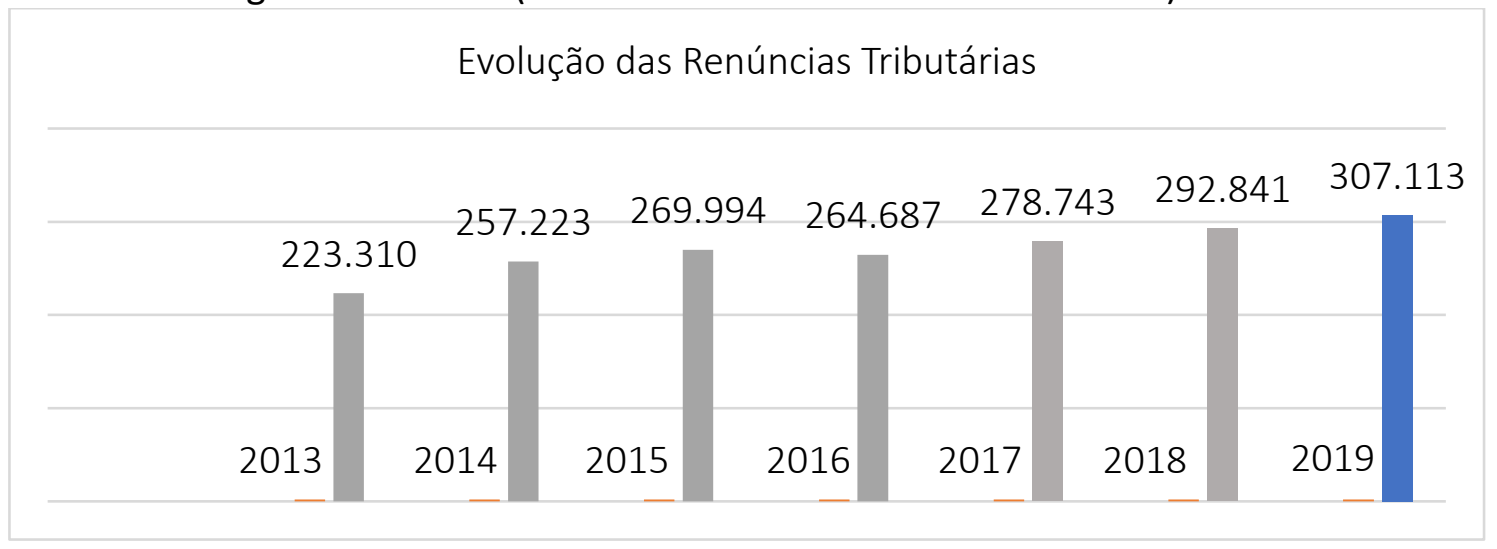

${ }^{18}$ Fonte: http://fundacaoanfip.org.br/site/page/5/?s=maiores+devedores. 
Fonte: Elaboração própria com base nos dados do Demonstrativo dos Gastos Tributários Bases Efetivas 2016 série 2014 a 2019 da Receita Federal do Brasil (2019). Os anos de 2013, 2014, 2015, 2016, 2017 e 2018 são das bases efetivas. $\mathrm{O}$ ano de 2019 é projeção.

A soma das renúncias tributárias nas contribuições sociais do Orçamento da Seguridade Social no período de 2013 a 2018, incluindo a projeção do ano de 2019, corresponde ao total de $\mathrm{R} \$ 1.893 .911$ trilhão.

Esses dados nos possibilitam afirmar que, ao se intensificar a crise do capital, as renúncias tributárias no Brasil são usadas como medidas de socorro ao capital, sendo que tal ajuda tem custado caro - a partir da tendência de continuidade e intensificação, poderá chegar à marca de 2 trilhões de reais, considerando o período de 2013 a 2020. Esse valor corresponde à mais-valia socialmente produzida pelos trabalhadores que, como já destacado, ao ser extraída pelo Estado, deveria compor o fundo público da seguridade social para garantir os direitos sociais previstos nesse sistema.

Além das renúncias tributárias, destacamos também os impactos causados pela DRU, executada também no âmbito do OSS. Segundo a Anfip (2018), de 2005 a 2017, a DRU desvinculou mais de $\mathrm{R} \$ 1,02$ trilhão, transferido para o âmbito do OF. Até 2015, ela operava com desvinculação de 20\% das contribuições sociais, passando em 2016 para 30\%, com vigência até 2023, como consequência do aprofundamento do ajuste fiscal brasileiro.

Estes valores desvinculados têm como destino o superávit primário, para pagamento dos serviços da dívida pública. Segundo Salvador (2017, p. 64), "na disputa do fundo público, os juros da dívida pública pagos pelo orçamento estatal são os principais alimentadores do Capital Portador de Juros e do capital fictício". Para Teixeira (2017, p. 109), em 2016, apesar de todas as despesas com juros e amortização da dívida, não tem sido possível conter o refinanciamento da dívida pública brasileira: “[...] no ano de 2015 correspondeu ao montante de $R \$ 571,6$ bilhões, equivalente a $25,8 \%$ do orçamento geral da União [...] também não provocaram a redução do tamanho do estoque da dívida pública federal, que alcançou $R \$ 3,1$ trilhões em 2016...", aumentando para $\mathrm{R} \$ 3,796$ trilhões em agosto de 2018, podendo chegar a R\$ 4,3 trilhões em 2019, segundo o Tesouro Nacional do Ministério da Fazenda (NERI, 2019a).

Contudo, Salvador (2017) destaca que essas medidas de ajuste fiscal têm se tornado obsoletas frente às necessidades crescentes de acumulação do capital, sobretudo, no que se refere à formação de valores no superávit primário. Portanto, se configura um Novo Regime 
Fiscal, aprovado pela Emenda Constitucional n.9 95, em 2016, que congela os gastos primários por vinte anos, desfinanciando, ainda, as políticas sociais.

Essa função do Estado de socorrer o capital com recursos públicos e de atacar os direitos sociais é uma das principais característica do atual estágio de acumulação, em que há um aprofundamento do papel do Estado de garantir a acumulação por espoliação, servindo de agente, ao lado da financeirização do capital e do livre comércio, sob orientação neoliberal. É próprio da função do Estado garantir processos como a liberação de mercados e a privatização de bens públicos, abandonando o bem-estar social para garantir as condições favoráveis para a acumulação do capital (HARVEY, 2014).

É nessa conjuntura que se configura a privatização da previdência num sentindo duplo: ao mesmo tempo que as renúncias tributárias socorrem diretamente o capital privado, também possibilitam que as contrarreformas sejam aprovadas, sustentadas - por exemplo pelo argumento de déficit orçamentário.

Ao mesmo tempo que o Estado provoca o desequilíbrio do orçamento previdenciário a partir das renúncias tributárias, impõe que o prejuízo seja socializado com a classe trabalhadora. Esse é o teor da nova contrarreforma expressa na Emenda Constitucional n.으 103/2019, que apresenta uma natureza mais perversa em comparação às demais contrarreformas, com ataques aos direitos previdenciários.

Apresentamos as alterações mais significativas na previdência social contidas na Emenda Constitucional n. 103/19: a definição de idade mínima para aposentadoria, sendo de 62 anos para mulheres e 65 anos para homens; o tempo mínimo de contribuição, de 20 anos para homens e 15 anos para as mulheres, trabalhadores do setor privado e, 20 anos para ambos os sexos dos trabalhadores do serviço público, havendo regras de transição para alguns casos; alteração no cálculo para o valor da aposentadoria de todos os trabalhadores do setor privado e público, passando a ser considerado a média de todas as contribuições, não existindo mais a exclusão das $20 \%$ contribuições mais baixas, com exceção dos servidores públicos que ingressaram no funcionalismo público até o ano de 2003 , sendo mantida a aposentadoria integral, cujo valor do benefício corresponderá ao último salário, desde que se aposentem com a idade mínima de 65 anos homens e 62 anos mulheres; alteração nas alíquotas de contribuição, que variam entre 7,5\% a $14 \%$ sobre os salários dos trabalhadores do setor privado e $7,5 \%$ até $22 \%$ incidentes nos salários dos servidores públicos; redução do valor da aposentadoria por incapacidade permanente, que corresponderá a $60 \%$ mais $2 \%$ 
correspondentes por ano de contribuição que exceda os 20 anos; redução do valor da pensão por morte, de $50 \%$ do valor, acrescido de mais $10 \%$ por dependente, respeitando o limite de $100 \%$ do valor da pensão; limite no acúmulo de benefícios, não sendo possível mais acumular $100 \%$ de todos os benefícios, com exceção de algumas categorias; aposentadoria de policiais e agentes penitenciais da esfera federal, sendo exigido, para ambos os sexos, 55 anos de idade mínima para novos integrantes, além dos 30 anos de contribuição e 25 anos na função; aposentadoria dos professores da educação básica, do setor privado, sendo necessário a idade mínima de 57 anos idade e 25 anos de contribuição para as mulheres e idade mínima de 60 anos e 25 anos de contribuição para os homens. Tais regras também valem para os professores do funcionalismo público, observando apenas a exigência de no mínimo 10 anos de serviço público e 5 no cargo; aposentadoria dos parlamentares, com idade mínima de 65 anos homens e 62 anos mulheres, além da exigência de $30 \%$ de contribuição faltante para se aposentar. Além disso, os novos parlamentares que ingressarem serão vinculados ao Regime Geral de Previdência Social, sendo extinto o antigo regime; criação da contribuição para os trabalhadores informais, semelhante ao do microempreendedor individual; e, por fim, aposentadoria especial dos expostos agentes nocivos, optando pelo sistema de ponto, que considera o tempo de exposição aos agentes nocivos, com níveis de maior risco, risco médio e baixo risco (BRASIL, 2019b).

\section{Considerações Finais}

O contexto atual da crise do capital tem acarretado significativas implicações para os direitos sociais a partir do aguçamento do ajuste fiscal, reforçando as relações de subordinação da política social à política econômica. É problemática a forma que o Estado tem arranjado para socorrer o capital, tendo em vista que é evidente o sacrifício dos interesses da maioria dos trabalhadores. É impensável a acumulação do capital nesse estágio sem a intervenção forte do Estado, de forma a possibilitar as condições favoráveis, mesmo que essas condições resultem na destruição de direitos que representam o progresso civilizatório, apesar de limitados nessa ordem.

Analisamos as renúncias tributárias no âmbito do orçamento das contribuições sociais das receitas previdenciárias no período entre 2013 a 2018 e nas demais contribuições sociais da Seguridade Social e constatamos que, em tempos de crise do capital, elas tendem a se intensificarem, socorrendo diversos setores da economia, tais como o industrial, os 
diversos tipos de empresas, os médios e pequenos empresários, a indústria farmacêutica, o agronegócio, entre outros, e de forma genérica, o capital. Na disputa pelo fundo público, os recursos estão sendo alocados de forma significativa, por exemplo, em favor desses capitalistas que são beneficiados pelas renúncias tributárias. Estamos falando do total de $\mathrm{R} \$$ 1,8 trilhão renunciado de 2013 a 2019, retirado do orçamento previdenciário e do OSS, sendo que as tendências de continuidade e intensificação das renúncias tributárias farão com que esse número aumente ao longo dos anos.

As implicações são catastróficas para a política social, tendo em vista que os dados corroboram a tendência de desfinanciamento da Seguridade Social. Essas políticas sociais se encontram cada vez mais esgotadas e limitadas frente aos seus compromissos, subfinanciadas, reforçando as tendências de focalização, seletividade e privatização. Em relação à Previdência Social, é insustentável o argumento de déficit nas contas previdenciárias apontadas pelo atual governo como base de sustentação da aprovação da Emenda Constitucional n. 103/2019. Confrontamos os valores renunciados no período em comparação com esse argumento, reafirmamos que não há déficit diante dos valores renunciados pelo Estado, bem como não há déficit levando em consideração as desvinculações realizadas pela DRU e ainda considerando os valores devidos ao INSS e os montantes gastos com a dívida pública.

Apesar dessas medidas de ajuste fiscal, o OSS vem, ainda, se mostrando superavitário, mantendo suas obrigações, pagando os benefícios e serviços das políticas de proteção social. Segundo a Anfip (2018), até 2015, o OSS fechou o seu resultado com saldo positivo, portanto, possuindo uma reserva positiva acumulada no fundo público, referente aos anos anteriores, podendo cobrir os saldos negativos registrados nos anos de 2016 e 2017. Mas a verdade é que essas reservas são almejadas pelos olhos do capital, seja o financeiro ou o produtivo, que segue através do Estado buscando todas as possibilidades possíveis de capturá-las, cabendo aos trabalhadores organizados mobilizar as massas para barrar esse ataque.

\section{Referências}

ANFIP - ASSOCIAÇÃO NACIONAL DOS AUDITORES FISCAIS DA RECEITA FEDERAL. Análise da seguridade social em 2017. Brasília: Anfip, 2018. 
BEHRING, Elaine Rosseti. Acumulação capitalista, fundo público e política social no Brasil. In: BOSCHETTI, E. R. et al. (Org.). Política Social no capitalismo: tendências contemporâneas. São Paulo: Cortez, 2008a.

BEHRING, Elaine Rosseti. Brasil em contrarreforma: desestruturação do Estado e perda de direitos. 2. ed. São Paulo: Cortez, 2008b.

BRASIL. Receita Federal. O que é o Simples Nacional? [2019]. Disponível em: http://www8.receita.fazenda.gov.br/SimplesNacional/Documentos/Pagina.aspx?id=3. Acesso em: 17 set. 2019.

BRASIL. Receita Federal. Demonstrativo dos gastos tributários: bases efetivas - 2016: série 2014 a 2019. Brasília: Ministério da Economia, 2019a. Disponível em: http://receita.economia.gov.br/dados/receitadata/renuncia-fiscal/demonstrativos-dosgastos-tributarios/arquivos-e-imagens/dgt-bases-efetivas-2016-serie-2014-a-2019-baseconceitual-e-gerencial.pdf. Acesso em: 18 set. 2019.

BRASIL. Emenda Constitucional n. 103, de 12 de novembro de 2019. Brasília, DF: Brasília, DF: Presidência da República, 2019b. Disponível em:

http://www.planalto.gov.br/ccivil_03/constituicao/emendas/emc/emc41.htm. Acesso em: 14 abr. 2019.

BRASIL. Governo Federal. Proposta de Emenda à Constituição - PEC n. 06. 2019. Modifica o sistema de previdência social, estabelece regras de transição e disposições transitórias, e dá outras providências. Brasília, DF: Presidência da República, 2019c. Disponível em: https://www.camara.leg.br/proposicoesWeb/prop_mostrarintegra? codteor=1712459\&filename=PEC+6/2019. Acesso em: 18/09/2019c.

CHESNAIS, François. Doze teses sobre a mundialização do capital. In: FERREIRA, C; SCHERER, A. F. O Brasil frente à ditadura do capital financeiro: reflexões e alternativas. Lajeado: UNIVATS, 2005.

FILGUEIRAS, Luiz. A. M. História do plano real. São Paulo: Boitempo, 2000.

GENTIL, Denise Lobato. A contra reforma da previdência social do governo Dilma Rousseff. Rio de Janeiro: Instituto de Economia da UFRJ, 2016. Disponível em: http://legis.senado.leg.br/sdleg-getter/documento/download/28719c82-669a-44dd-878f74a8d44ee609. Acesso em: 18 set. 2019.

GRANEMANN, Sara. Fundos de pensão e a metamorfose do "salário em capital". In: SALVADOR, Evilásio et al. (Org.). Financeirização, fundo público e política social. São Paulo: Cortez, 2012.

HARVEY, David. Condição Pós-moderna: uma pesquisa sobre as origens da mudança cultural. São Paulo: Edições Loyola, 1992.

HARVEY, David. O novo imperialismo. São Paulo: Edições Loyola, 2014.

IBGE. PNAD Contínua: taxa de desocupação é de 12,3\% e taxa de subutilização é $25,0 \%$ no trimestre encerrado em maio de 2019. Agência IBGE Notícias, Rio de Janeiro, 28 jun. 2019. 
Disponível em: https://agenciadenoticias.ibge.gov.br/agencia-sala-de-imprensa/2013agencia-de-noticias/releases/24908-pnad-continua-taxa-de-desocupacao-e-de-12-3-e-taxade-subutilizacao-e-25-0-no-trimestre-encerrado-em-maio-de-2019. Acesso em: 18 set. 2019.

MANDEL, Ernest. A crise do capital: os fatos e sua interpretação marxista. São Paulo: Ensaio, 1990.

MARX, Karl. O Capital. 26. ed. Rio de Janeiro: Civilização Brasileira, 2008. livro I, v. II.

MOTA, Ana Elizabete. Cultura da crise e seguridade social. 7. ed. São Paulo: Cortez, 2015.

NERI, Marcelo C. A escalada da desigualdade: qual foi o impacto da crise sobre a distribuição de renda e a pobreza? Rio de Janeiro: FGV, 2019a.

NERI, Marcelo C. Sem 'norte', serão 15 anos para Brasil voltar à pobreza de 2014. Folha de São Paulo, São Paulo, 20 ago. 2019b. Mundo Brasil. Disponível em:

http://agenciabrasil.ebc.com.br/economia/noticia/2018-09/divida-publica-sobe-098-eatinge-r-3785-trilhoes-em-agosto. Acesso em: 17 set. 2019.

OLIVEIRA, Francisco de. Os direitos do antivalor: a economia política da hegemonia imperfeita. Petrópolis: Vozes, 1998.

SALVADOR, Evilasio. Fundo público e seguridade social no Brasil. São Paulo: Cortez, 2010.

SALVADOR, Evilasio. O desmonte do financiamento da seguridade social em contexto de ajuste fiscal. Revista Ser Social e Sociedade, São Paulo, n. 130, p. 426-446, set./dez. 2017.

SOUZA, Giselle; SOARES, Morena Gomes Marques. Contrarreformas e recuo civilizatório: um breve balanço do governo Temer. SER Social, Brasília, v. 21, n. 44, p. 11-28, jan.-jun. 2019.

TEIXEIRA, Solange M. Ataques ao OSS: ofensiva do capital contra o trabalho. Advir, Rio de Janeiro, n. 36, p. 99-111, jul. 2017.

Recebido em: 12.09.2019

Aceito em: 07.10.2020 